\title{
Subclinical ADHD-Symptoms Are Associated with Executive-Functioning and Externalizing Problems in College Students without ADHD-Diagnoses
}

\author{
Allen J. Brown ${ }^{1} \&$ Beth M. Casey ${ }^{2}$ \\ ${ }^{1}$ Departments of Criminal Justice and Psychology, School of Justice and Social Science, Anna Maria College, \\ Paxton, USA \\ ${ }^{2}$ Department of Counseling, and Applied Developmental, and Educational Psychology, Lynch School of \\ Education, Boston College, Paxton, USA \\ Correspondence: Allen J. Brown, Departments of Criminal Justice and Psychology, School of Justice and Social \\ Science, Anna Maria College, Paxton, MA 01612, Paxton, USA. Tel: 1-617-448-5813. E-mail: \\ abrown@annamaria.edu
}

Received: October 18, 2015

Accepted: November 8, $2015 \quad$ Online Published: April 7, 2016

doi:10.5539/jedp.v6n1p204

URL: http://dx.doi.org/10.5539/jedp.v6n1p204

\begin{abstract}
This study investigated whether problem behaviors, typically associated with a clinical diagnosis of ADHD, would also be associated with subclinical ADHD symptoms within a non-clinical college sample. These are symptoms characteristic of ADHD, which are insufficient to warrant a DSM-IV diagnosis of ADHD. Self-ratings of behaviors known to be comorbid with ADHD (Oppositional-Defiant Disorder (ODD) behaviors, risk-taking, and Executive-Functioning (EF) problems) were examined as predictors of self-ratings of ADHD symptoms. Measures of ODD symptoms, risk-taking, and EF behavioral problems (related to poor management of time) significantly predicted ADHD symptoms, as measured by Barkley's ADHD Combined Subscale. These predictors accounted for $26 \%$ of the variance. The same measures predicted symptoms of ADHD, Inattentive type, as measured by Barkley's Inattentiveness (IA) Subscale, and accounted for 30\% of the variance. For the Hyperactivity-Impulsivity Subscale (HI), the ODD measure significantly entered the equation, while the other two measures were borderline significant, accounting altogether for $10 \%$ of the variance. As hypothesized, the EF measure was the strongest predictor for IA, and the ODD measure was the strongest predictor for HI. In conclusion, problem behaviors comorbid with a formal clinical ADHD diagnosis were found to be significantly associated with subclinical ADHD symptoms within a non-clinical sample of college students, as indicated by the substantial proportion of the variance they accounted for in predicting the Barkley's' Combined and Inattentiveness Subscales, and to a lessor extent for the Hyperactivity/Impulsivity Subscale. This indicates that college students with ADHD symptoms may have substantial problems not only with their ADHD symptoms, but also with executive functioning and externalizing behaviors associated with these symptoms.
\end{abstract}

Keywords: adult ADHD, risk-taking behaviors, addictive behaviors, executive functioning, Oppositional Defiant Disorder, community sample

\section{Introduction}

\subsection{Comorbidities Associated with ADHD}

A striking characteristic of Attention Deficit Hyperactivity Disorder (ADHD) is the diverse range of comorbid conditions associated with its diagnosis. These consist of externalizing behaviors, including Oppositional Defiant Disorder (ODD) as well as risk-taking in a number of domains, such as substance abuse, gambling, risk-taking associated with driving, and risky sexual activities (Abrantes et al., 2006; Biederman et al., 1993, Kaye et al., 2014; Murphy et al., 2002). In addition, there is a strong comorbidity between diagnoses of ADHD and Executive Functioning (EF) disorders, such as poor management of time (Barkley et al., 2001; Toplak et al., 2006; Willcutt et al., 2005).

The rationale for the present research is based on a conceptualization of ADHD as being part of a normal continuum. In contrast to the view of ADHD as a categorical (all-or-none) diagnosis, a number of researchers 
identified ADHD as the lower-end of a normal continuum of ability to modulate attentional processes and behavioral inhibition/control (Barkley, 1998; Levy et al., 1997; Tannock, 1999). Therefore, individuals who are below the diagnostic cutoff, but with some of the same ADHD symptoms, would still be at risk for some of the same externalizing and executive problems as those with the ADHD diagnosis.

According to Marcus, Norris, and Coccaro (2012), "the vast majority of studies that have examined the latent structure of ADHD in children and adolescents have concluded that ADHD has a dimensional rather than categorical structure" (p. 782). Their findings (2012), using adults from both clinical and community samples provide strong support for the view of ADHD as the extreme lower end of a normal continuum. Further support is provided by a recent study by Carragher and her associates (Carragher et al., 2014) using a large representative sample. Thus, evidence indicates that individuals with a clinical diagnosis of ADHD differ in degree rather than kind from those with subclinical ADHD whose symptoms do not reach the diagnostic-cutoff for ADHD.

\subsection{Purpose of This Study}

In the present study, we investigated college students from a community sample to address our research goals relating to the investigation of students with subclinical ADHD symptoms. Our first step was to define a non-clinical sample by excluding college students who fit the formal diagnosis for any of the ADHD subtypes. With the remaining students, a key question for the present study was whether problem behaviors comorbid for a clinical diagnosis of ADHD were also significantly correlated with ADHD symptoms within a non-clinical sample, such that individuals with higher subclinical ADHD symptoms would also show higher externalizing and executive functioning problems. Furthermore, we examined whether the pattern of relations across these different behavioral problems (ODD, risky behaviors, and executive functioning) would be associated in this non-clinical sample in a parallel way to those with a formal diagnosis of the different subtypes of ADHD.

To be consistent with the DSM-IV, we used three of Barkley's ADHD adult rating scales by dividing Barkley's Adult ADHD rating scale-IV (2011) into three subtypes or categories: Hyperactive/Impulsive (HI), Inattentive (IA), and Combined HI and IA. For the present study, for each subtype of ADHD, we first had to identify those who reached the ADHD diagnosis cutoff, and then exclude students from the analysis who fit the cutoff for any of the subscales. Based on Barkley's adult ADHD self-rating subscales (2011), we operationally defined the clinical diagnosis of ADHD for each subscale as occurring within individuals who reported sufficient symptoms to reach Barkley's criteria for mildly, moderately, or severely symptomatic. Thus, our non-clinical sample included students ranging from those just missing the diagnostic cutoff all the way down to those with little or no symptoms.

To assess problem behaviors associated with ADHD comorbidities, we included students' self-rating scales of: (1) oppositional defiant behaviors, (2) a range of risk-taking behaviors, and (3) poor executive functioning, relating to poor management of time as predictors of each adult-ADHD subscale. From a theoretical perspective, the present study makes a contribution to the literature on non-clinical ADHD samples by simultaneously examining the pattern of relationships across these diverse types of externalizing and executive functioning problems as predictors of the different subtypes of ADHD symptoms.

\subsection{Research Literature on a Diagnosis of ADHD and Risk-Taking Behaviors}

Extensive research has shown that an ADHD diagnosis is associated with a range of externalizing behaviors involving excessive risk-taking in children and adults. Excessive risk-taking behaviors identified in adults with ADHD include: substance abuse (De Alwis et al., 2014; Murphy et al., 2002), gambling (Groen et al., 2013; Rugle \& Melamed, 1993), risky driving (Kaye et al., 2014), and risky sexual behaviors (Flory et al., 2006).

\subsubsection{Addictive Behaviors}

There is strong evidence for an association between ADHD and addictive behaviors. Substance abuse disorders, in particular, have been found in individuals with IA as well as Combined and HI subtypes (De Alwis et al., 2014; Murphy et al., 2002; Roberts et al., 2014). There is also evidence of increased substance abuse among individuals from community samples who had ADHD symptoms before age 18, but who did not meet the criteria for a formal ADHD diagnosis (De Alwis et al., 2014). A major recent study (Carragher et al., 2014) used epidemiological methods to examine a representative sample of adult participants reporting on ADHD symptoms as well as lifetime use and DSM-IV abuse/dependence (SUD) on alcohol, nicotine, cannabis, cocaine, sedatives, stimulants, and heroin/opiates through the National Epidemiological Survey on Alcohol and Related Conditions data set (NESARC). These researchers concluded that a childhood diagnosis of ADHD across subtypes is on a continuum as part of a common externalizing liability, such that it predicts later externalizing disorders related to 
substance abuse. In addition, within studies making comparisons between ADHD subtypes and normal controls, greater addictive gambling has also been found for both Combined and HI subtypes of ADHD, but less so with IA subtype (Groen et al., 2013; Toplak, Jain, \& Tanner, 2005). However, this association between gambling and ADHD is less common in adults than in adolescents (see review by Groen et al., 2013).

\subsubsection{Driving and Sexual Activities}

In relation to driving, research has shown that a diagnosis of ADHD creates a higher risk for adverse driving outcomes, with a high incidence of speeding violations and car accidents (Barkley et al., 2002; Barkley \& Murphy, 2011; Kaye et al., 2014; Weiss \& Hectman, 1993). Driving problems have been found for ADHD individuals with both HI and IA diagnoses (Barkley et al., 2002). In addition, there is also evidence of ADHD as a predictor of an earlier initiation of sexual activity, more sexual partners, and a higher frequency of casual, unprotected sex (Abrantes et al., 2006; Barkley et al., 2006; Flory et al., 2006). Risky sexual behaviors are more likely to be found with HI than IA (Sarver et al., 2014). Furthermore, an association of risky sexual behaviors with ADHD symptoms has been found in community samples as well (Price \& Hyde, 2009; White \& Buehler, 2012).

\subsubsection{Associations across Risky Behaviors}

The preference for risky behavior among individuals with ADHD seems to encompass a wide range of high-risk activities (Douglas \& Peters, 1979; Douglas, 1983). ADHD research findings suggest there is a link across different types of risk-taking behaviors. For example, drug abusers with comorbid ADHD symptoms also had greater overall number of driving offences than those in the substance abuse clinic without comorbid ADHD (Kaye et al., 2014). Among juveniles associated with drug-abuse arrests, substance abusers with ADHD were found to be more likely to have risky sexual behaviors than substance abusers without ADHD (Sarver et al., 2014). A similar association was found between drugs and risky sexual behaviors in a longitudinal study of children with ADHD (Winters et al., 2008).

These findings on the range of risky behaviors associated with ADHD are consistent with the view that risk-taking in individuals diagnosed with ADHD is a more general phenomenon rather than a problem unique to specific risk-taking behaviors within that individual. Consequently, the present study took a different approach by examining risk-taking behaviors as an inclusive category across a wide range of types of risky behaviors in this non-clinical sample. As one of the predictors of the ADHD subscales within our sample, we included a composite Risk-taking Scale, assessing students' self-report of risky behaviors across a number of risk-taking behaviors (including addictive behaviors, and risk-taking behaviors with cars and sexual activities). We hypothesized that this composite measure assessing self-reported risk-taking behaviors across the different risk-taking categories would form a reliable scale, and that this scale would predict ADHD symptoms within our non-clinical community sample.

\subsection{Research Literature on a Diagnosis of ADHD and ODD}

There is substantial literature suggesting a strong relationship between Oppositional Defiant Disorder (ODD) and ADHD (Newcorn \& Halperin, 1994; Jensen et al., 1997), a relationship that extends from childhood to adulthood. (Barkley et al., 1996; Biederman et al., 1993, Murphy et al., 2002). In general, greater comorbidity between ADHD and ODD has been found with the HI subtype than the IA subtype (Murphy et al., 2002). Based on our hypotheses, we predicted that those with subclinical ADHD symptoms, particularly with an HI subtype would also be prone to externalizing behaviors associated with ODD even within a non-clinical college sample. Thus, a self-report measure of oppositional defiant behaviors, Barkley's Adult Oppositional Defiant Disorders Scale, was included in the present study as a predictor of ADHD. The inclusion of the measure of ODD also served as a control variable to rule out the possibility that any association between subclinical ADHD and risk-taking behaviors might, in fact, be due to both their associations with ODD.

\subsection{Research Literature on a Diagnosis of ADHD and Executive Functioning Problems}

It remains likely that ADHD deficits are heterogeneous, involving a variety of contributing factors (Hulme \& Snowling, 2009). In addition to increasing externalizing behaviors, ADHD is associated with diminishment in effective deployment of executive functions. There is substantial research indicating a strong association between ADHD and impaired Executive Functions (EF) (Toplak et al., 2006; Willcutt et al., 2005), and this association has been found across a range of ages (Abedi, Aghababaei, Sharbaf Zadeh, \& Zamani, 2014). Both performance-based cognitive measures of poor executive functioning, such as planning and response inhibition, and self-rating measures of executive functioning problems have been used to assess these types of processing 
problems, and recently, researchers have begun to conclude that these types of measures assess different underlying mental constructs (Barkley, 2012; Toplak, West, \& Stanovich, 2013). In their literature review, Toplak and her colleagues (Toplak et al., 2013) consider the cognitive measures of executive function to be assessing the efficiency of cognitive abilities, while self-report assesses success in goal pursuits. Barkley (2012) proposes that the self-rating measures are better predictors of executive functioning problems associated with diagnoses of ADHD.

In the present study, we chose to use self-report measures to focus on poor management of time, a common symptom of impaired EF, and one that is often associated with ADHD (Barkley et al., 2001; Metevia, 2001; Toplak et al., 2006). ADHD has been associated with a deficiency in making judgments involving long intervals of time and time reproduction rather than a general deficit in perception of time (Barkley et al., 2001; Radonovich \& Mostofsky, 2004). In Barkley's Self-Management-to-Time subscale from his Deficits in Executive Functioning Scale (DEFS), he found evidence that this EF subscale correlated .91 with a diagnosis of IA and .71 with a diagnosis of HI (Barkley \& Murphy, 2011). Kamradt, Ullsberger, and Nikolas (2014) found poor time management was related more to an IA diagnosis than HI. In addition, Barkley and Murphy (2011) found evidence of poor management of time in students from a non-clinical sample with subclinical ADHD symptoms. Thus, this EF subscale was included as a predictor of ADHD in our non-clinical college sample.

\subsection{Design of the Study}

Research questions were examined through self-report survey questionnaires administered to a college sample. Hypotheses were examined through regression analyses predicting each of the three Barkley measures of Adult ADHD (including the Combined, HI, and IA Subscales). In each analysis, only participants who did not reach the cutoff for any ADHD diagnosis or who had not self-reported an ADHD diagnosis were included in the non-clinical college sample. In using a regression approach to analyzing the data, we examined a continuum of behaviors within the non-clinical sample, rather than using cutoffs based on evidence for or absence of ADHD symptoms. Thus, we were predicting that those higher on comorbidity-related symptoms would also be higher on ADHD subclinical symptoms (all below the diagnostic cutoff). In addition, we predicted that those with intermediate problem behaviors of these types would have fewer ADHD symptoms, and those with little or no comorbidity-related problem behaviors would have little or no ADHD symptoms.

We decided that in the regression analyses, a measure was needed to control for social desirability effects. Many questions across the different rating scales might be considered as asking participants to rate themselves as having undesirable characteristics. The Marlowe-Crowne Social Desirability Scale (Crowne \& Marlowe, 1960) was included within the regression analyses to control for the possibility that any association between these comorbid behaviors and the measures of ADHD might just be due to a negative response bias across measures.

To summarize, the present study was designed to determine whether problem behaviors associated with formal ADHD clinical subtype diagnoses would show a similar association with ADHD subtype symptoms within a non-clinical college community sample. Based on the literature, we hypothesized that greater ODD behaviors (as measured by Barkley's Oppositional Defiant Disorders Scale) would be the strongest predictor of HI symptoms, and difficulty with executive functioning (as measured by Barkley's DEFS subscale assessing Self-Management-to-Time) would be the strongest predictor of IA ADHD symptoms. Greater risk-taking behaviors (as measured by a composite Risk-taking Scale) would be associated with higher ADHD symptoms across the subtypes.

Thus, a key purpose was to determine whether problem behaviors comorbid for a clinical diagnosis of ADHD would also be significantly correlated with ADHD symptoms within a non-clinical sample. This evidence is important theoretically because it would further support the view of ADHD as the extreme lower end of a normal continuum. From a practical level, the purpose was to provide more information to universities and colleges about students without a clinical diagnosis of ADHD who may still have a constellation of: ADHD symptoms, externalizing problems, and executive functioning difficulties that may provide obstacles to their academic success.

\section{Methods}

\subsection{Participants}

The convenience sample consisted of undergraduate students at a small private Catholic college who gave their written consent to participate in the study. Note that this research has been approved by the college's Institutional Review Board. Questionnaire packets were administered to 165 students in classes (78 males; 87 
females), ages 18-36 years of age, who had signed informed consent forms. The mean age of the sample was 19.80 years $(S . D .=1.84)$. For both parents, $1-3$ years of college or technical/vocational school was reported as median years of education. According to Barkley's ADHD adult rating scale (2011), scores from the $93^{\text {rd }}$ percentile and above are diagnosed as being mildly, moderately, or severely symptomatic.

To identify the students to be retained in the non-clinical sample, for all subscales, we excluded any participant who reached the diagnostic cutoff for any of the ADHD subscales (Barkley's Adult ADHD-Combined (Combined) Subscale, the Hyperactivity/Impulsivity (HI) Subscale, and the Inattentiveness (IA) Subscale). Because using different methods to identify college students with ADHD has resulted in different prevalence estimates for the disorder (Green \& Rabiner, 2013), we used a second criterion for exclusion of students from the sample. We omitted any one who (mistakenly or not) self-reported a diagnosis of ADHD at some point in their lives. Although it is very likely that the students' self-reports were inflated, we used this strict criterion to ensure that our non-clinical sample excluded anyone who might have been previously diagnosed with some type of ADHD. Students who self-reported a prior diagnosis of ADHD at some point in their lives included $20 \%$ of the college sample with the average age of diagnosis being 11.5 years of age $(S . D .=3.70)$. Again, this is probably an over-reporting, based on students' imprecise recall, and should not be taken as an accurate diagnosis. Nevertheless, to be conservative, we excluded these participants as well as those who fit a particular Barkley Adult ADHD subtype. The non-clinical sample included 109 participants (65 females; 44 males).

For the Combined diagnosis, $14 \%$ of the students in the original convenience sample reached the diagnostic cut-off. For the HI diagnosis, $7 \%$ of the participants reached the diagnostic cut-off. For the IA diagnosis, $10 \%$ of the participants reached the diagnostic cut-off (see Table 2). For comparison purposes, Murphy and Barkley (1996a) reported that for a representative sample of adults between the ages of 17 and 84, individuals meeting the ADHD-Combined diagnosis showed a rate of $4.7 \%$. Thus, the students in the present sample either are over-estimating symptoms when rating themselves on the individual items in the ADHD subscales, and/or this college sample has more ADHD symptoms than the general population.

For the non-clinical students retained in the study, Table 1 provides the descriptives for these students, and Table 2 shows an overview of the number of students falling into each category (for both those excluded and included within the sample). For those included in the data analysis in the present study (the non-clinical sample of college students), 109 participants (66\%) of the convenience sample were included in the analyses for the three ADHD subtypes. Note that conservative criteria were used to include students within the non-clinical sample.

Table 1. Descriptives for the variables for the non-clinical participants included in the study

\begin{tabular}{|c|c|c|c|c|c|}
\hline & $\mathrm{N}$ & Minimum & Maximum & Mean & S.D. \\
\hline $\begin{array}{l}\text { Adult ADHD Combined } \\
\text { subscale }\end{array}$ & 109 & 18.00 & 38.00 & 25.86 & 5.06 \\
\hline $\begin{array}{l}\text { Adult Inattentiveness } \\
\text { ADHD subscale }\end{array}$ & 109 & 9.00 & 20.00 & 12.63 & 2.90 \\
\hline $\begin{array}{l}\text { Adult ADHD } \\
\text { Hyperactivity/ } \\
\text { Impulsivity subscale }\end{array}$ & 109 & 8.00 & 21.00 & 13.23 & 3.25 \\
\hline $\begin{array}{l}\text { Social Desirability } \\
\text { scale }\end{array}$ & & .00 & 13.00 & 6.94 & 2.76 \\
\hline $\begin{array}{l}\text { Disorder of Executive } \\
\text { Functioning scale }{ }^{\mathrm{a}}\end{array}$ & & .00 & 26.00 & 8.11 & 5.12 \\
\hline Risk-taking scale & & -.51 & .95 & -.11 & .33 \\
\hline $\begin{array}{l}\text { Oppositional Defiant } \\
\text { Disorder scale }\end{array}$ & & .00 & 17.00 & 4.32 & 3.07 \\
\hline
\end{tabular}

${ }^{a}$ Barkley Disorder of Executive Functions Subscale Factor 1: Self-Management-to-Time 
Table 2. Number of participants within each category either excluded from or included within the sample of 165 students assessed in the study

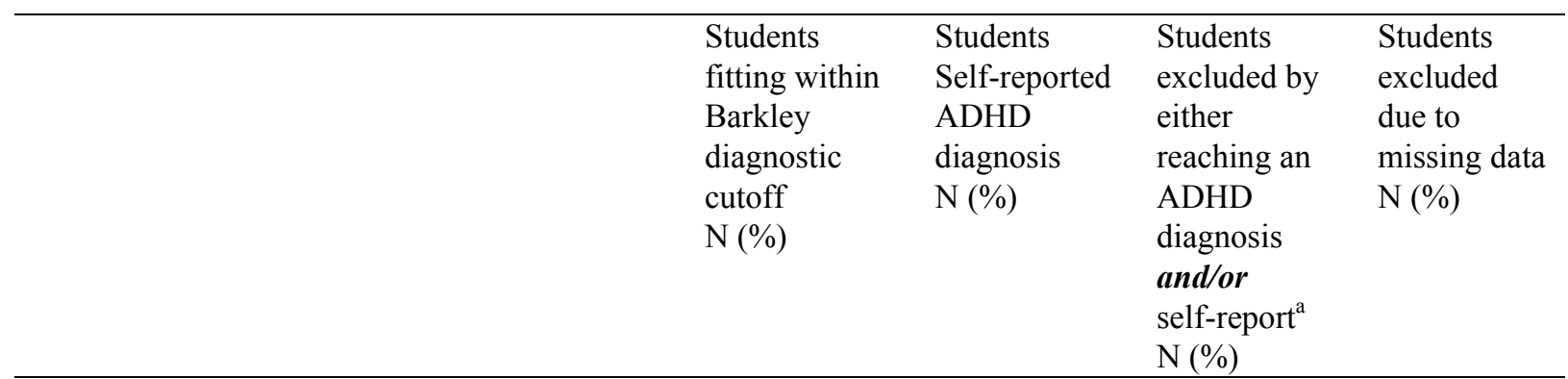

EXCLUDED: Total Students excluded from non-clinical sample for each ADHD subscale analysis

\begin{tabular}{|c|c|c|c|c|}
\hline Combined ADHD diagnosis & $23(14 \%)$ & $33(20 \%)$ & $47(26 \%)$ & $7(4 \%)$ \\
\hline Inattentiveness diagnosis & $17(10 \%)$ & $33(20 \%)$ & $45(27 \%)$ & $7(4 \%)$ \\
\hline Hyperactivity/Impulsivity diagnosis & $12(7 \%)$ & $33(20 \%)$ & $39(24 \%)$ & $9(5 \%)$ \\
\hline $\begin{array}{l}\text { INCLUDED: Total students included in the } \\
\text { non-clinical sample for each ADHD subscale } \\
\text { analysis }\end{array}$ & & & & $\begin{array}{l}\text { Final N } \\
\text { included in } \\
\text { each ADHD } \\
\text { analysis } \\
\mathrm{N}(\%) \\
\end{array}$ \\
\hline Combined ADHD diagnosis & & & & $111(67 \%)$ \\
\hline Inattentiveness diagnosis & & & & $113(68 \%)$ \\
\hline Hyperactivity/Impulsivity diagnosis & & & & $117(71 \%)$ \\
\hline
\end{tabular}

${ }^{a}$ Note that there was some overlap between students who were excluded due to a diagnosis of ADHD based on the Barkley scale and those who had self-reported ADHD.

\subsection{Independent Measures}

\subsubsection{Risk-Taking Scale}

The items in the survey relating to risk-taking behaviors were developed for the study, using the format and questions taken from the items used for the 1997 Youth Risk Behavior Survey for college students developed by the U.S. Department of Health and Human Services (Center for Disease Control, 1998). Some items were recoded so that all high scores meant high risk-taking. Because the items did not all have the same format, the ratings for each item in the questionnaire were converted into z-scores to combine them into a composite scale. The items across the different risk-taking behaviors (including drug-use, alcohol-use, gambling, risky driving behaviors, and risky sexual behavior) formed a coherent scale, showing strong reliability across items for the present convenience sample; Cronbach's Alpha for this Risk-taking Scale was .82 (See Appendix for item descriptions and the Likert rating scales for the items.). Support for the validity of this composite measure of risk-taking was provided by the significant correlations between this composite scale and all three ADHD subscales (Combined, IA, and HI) (see Table 3).

\subsubsection{ODD Scale}

The ODD Scale is part of Barkley's Adult Behavior Rating Scale-Self-Report of Current Behavior (Form 10) (1997b). Participants were asked to "Circle the number that best describes your behavior over the past 6 months", and the response options consist of a 4-point Likert scale, (0) Never or rarely, (1) Sometimes, (2) Often, (3) Very often. See Barkley (1997b) for methodological details. The reliability for the present convenience sample was strong; Cronbach's Alpha $=.85$.

\subsubsection{EF Scale}

The items from Barkley's Self-Management-to-Time subscale from his DEFS include the 10 items that loaded most heavily on Factor 1: Self-Management-to-Time. Participants were asked to "Circle the number that best describes your behavior over the past 6 months", and the response options consist of a 4-point Likert scale, (0) 
Never or rarely, (1) Sometimes, (2) Often, (3) Very often. See Barkley and Murphy (2011) for methodological details. The reliability for the present convenience sample was strong; Cronbach's Alpha $=.88$.

\subsubsection{Social Desirability Scale}

Higher scores on this measure represent the need to obtain approval by responding in a culturally acceptable manner. Responses were based on True or False. Participants who score low on this measure are more willing to say negative things about themselves. In the present study, we used the Reynolds Short Form A of the Crowne-Marlowe Social Desirability Scale. See Reynolds (1982) for methodological details. The Social Desirability Scale for the convenience sample in this study had a Cronbach's Alpha of .66, which is slightly below the desired .70 cutoff.

\subsection{Dependent Measures}

Each of the 18 items from Barkley Adult ADHD Rating Scale-IV (BAARS-IV) (Barkley, 2011) was used as the measure of ADHD. Barkley's items were adapted from the DSM-IV criteria for ADHD (APA, 1994), and the Likert scales were normed on a sample of 1,249 adults of ages 18-89. The range of possible responses went from (1) Never or rarely, (2) Sometimes, (3) Often, and (4) Very often. To compare to the normative sample, the following are the means and standard deviations for each subscale for the total convenience sample as whole, including those with ADHD diagnoses (Combined: $M=29.01$, S.D. $=9.28 ; \mathrm{HI}: M=15.01$, S.D. $=5.06$; IA: $M=$ $14.28, S . D .=4.88)$. The reliabilities for the present convenience sample were excellent (Cronbach's Alpha for Combined $=.91 ; \mathrm{IA}=.89 ; \mathrm{HI}=.85$ ).

\section{Results and Discussion}

\subsection{Descriptives}

The descriptives for variables for the non-clinical college sample included in the study are in Table 1. The average score for the Combined ADHD subscale was 25.86, ranging from 18 to 38. Given the Combined ADHD diagnostic cutoff, the highest score that students could reach and still remain in the study was 38 . The average score for the IA ADHD subscale was 12.63, ranging from 9 to 20. Given the IA diagnostic cutoff, the highest score that students could reach and still remain in the study was 20. The average score for the HI ADHD subscale was 13.23 , ranging from 8 to 21 . Given the HI diagnostic cutoff, the highest score that students could reach and still remain in the study was 22 (personal communication, Barkley, June 11, 2015).

\subsection{Correlations}

Pearson Product Moment Correlation Coefficients were calculated between the independent variables and the three subtypes of ADHD for the non-clinical sample (see Table 3). It should be noted that even in this non-clinical ADHD college sample, all three of the measures of ADHD comorbidities, including externalizing problems (Risk-taking and ODD) and executive functioning problems (Self-Management-to-Time) showed significant correlations with the three subscales of ADHD, ranging from .20 to .50 .

\subsection{Regression Analyses}

Next, three separate regression analyses were conducted with the ADHD measures (Combined, HI, and IA) as the dependent measures. For Model 1, just the social desirability control variable was entered into the regression equations. In Model 2, in addition to this control variable, the ODD rating scale, the EF Self-Management-to-Time Scale, and the Risk-taking Scale were entered as predictor variables. 
Table 3. Correlations of Barkley's dependent variables of ADHD-Combined, hyperactivity/impulsivity, and Inattentiveness with the independent variables for the non-clinical community sample

\begin{tabular}{llll}
\hline & $\begin{array}{l}\text { ADHD-Combined } \\
\text { Subscale }\end{array}$ & $\begin{array}{l}\text { Hyperactivity/Impulsivity } \\
\text { Subscale }\end{array}$ & Inattentiveness Subscale \\
\hline Social Desirability Scale & $-.25^{* *}$ & -.13 & $-.29^{* *}$ \\
$\begin{array}{l}\text { Oppositional Defiant } \\
\begin{array}{l}\text { Disorder Scale } \\
\text { Functioning Scale }\end{array}\end{array}$ & $.38^{* *}$ & $.25^{* *}$ & $.37^{* *}$ \\
Risk-taking Scale & $.41^{* *}$ & $.20^{*}$ & $.50^{* *}$ \\
\hline
\end{tabular}

${ }^{\mathrm{a}}$ Barkley Disorder of Executive Functions Subscale Factor 1: Self-Management-to-Time

${ }^{\mathrm{b}}$ Item subtypes within the Risk-taking Scale. $\mathrm{p}<.05^{*} ; \mathrm{p}<.01^{*}$

Table 4. Predictors of Barkley's ADHD-Combined subscale for the non-clinical community sample

\begin{tabular}{|c|c|c|c|c|}
\hline & B-weights & $\begin{array}{ll}95 \% & \text { Conf. } \\
\text { Interval } & \end{array}$ & Beta-weights & R2 inc \\
\hline Model 1 & & & & $.06 * *$ \\
\hline $\begin{array}{l}\text { Marlowe-Crown } \\
\text { Social Desirability } \\
\text { Scale }\end{array}$ & -.46 & -.80 to -.11 & $-.25 * *$ & \\
\hline Model 2 & & & & $.26^{* *}$ \\
\hline $\begin{array}{l}\text { Marlowe-Crown } \\
\text { Social Desirability } \\
\text { Scale }\end{array}$ & -.00 & -.33 to .33 & -.00 & \\
\hline $\begin{array}{l}\text { Oppositional Defiant } \\
\text { Disorder Scale }\end{array}$ & .50 & .22 to .79 & $.31 * *$ & \\
\hline $\begin{array}{l}\text { Executive } \\
\text { Functioning } \\
\text { Disorder Scale }^{\mathrm{a}}\end{array}$ & .35 & .19 to .52 & $.36 * *$ & \\
\hline $\begin{array}{l}\text { Risk-taking } \\
\text { Scale }\end{array}$ & 3.36 & .88 to 5.74 & $.22 *$ & \\
\hline
\end{tabular}

$.30 * *$

${ }^{\mathrm{a}}$ Measured by Barkley's Disorder of Executive Functions Subscale Factor 1: Self-Management-to-Time. ${ }^{+} \mathrm{p}$ $<.10>.05 ; * \mathrm{p}<.05 ; * * \mathrm{p}<.01$.

\subsubsection{ADHD-Combined}

In the Combined analysis, the control variable alone accounted for $6 \%$ of the variance in Model 1. For Model 2, which included the predictor variables as well as the control variable, $30 \%$ of the variance was accounted for (see Table 4). In Model 1, the Social Desirability variable entered the equation negatively, with individuals with a lower social desirability scale more likely to be higher in ADHD-Combined symptoms. This measure controlled for a negative response bias, because many items for the scales are framed as negative self-ratings, which may inflate the associations between ADHD and other comorbid conditions (Note: this association was also found in Model 1 for the IA analysis.).

For the predictor variables, all three significantly entered the equation, with the EF Self-Management-to-Time Subscale showing the largest effect, the ODD Scale was second, and the Risk-taking Scale was last. Thus, in this non-clinical college sample, those with combined ADHD symptoms but no diagnosis, showed a similar pattern 
of findings in terms of increased comorbidity for externalizing and EF problems, as those with the full diagnosis. Furthermore, the effects of these types of problems were substantial, accounting for over a quarter of the variance in ADHD-Combined symptoms in this community sample.

\subsubsection{Inattentiveness}

For the IA measure, the control variable accounted for $9 \%$ of the variance in Model 1. For Model 2, which included the predictor variables as well as the control variable, $36 \%$ of the variance was accounted for (see Table 5). The pattern of findings for the IA measure of ADHD was identical to the Combined measure; the EF Self-Management-to-Time scale was the strongest predictor for the IA measure. Furthermore, the effects of behaviors comorbid with a diagnosis of ADHD were substantial, accounting for almost a third of the variance in IA ADHD symptoms in this community sample.

Table 5. Predictors of Barkley's inattentiveness subscale for the non-clinical community sample

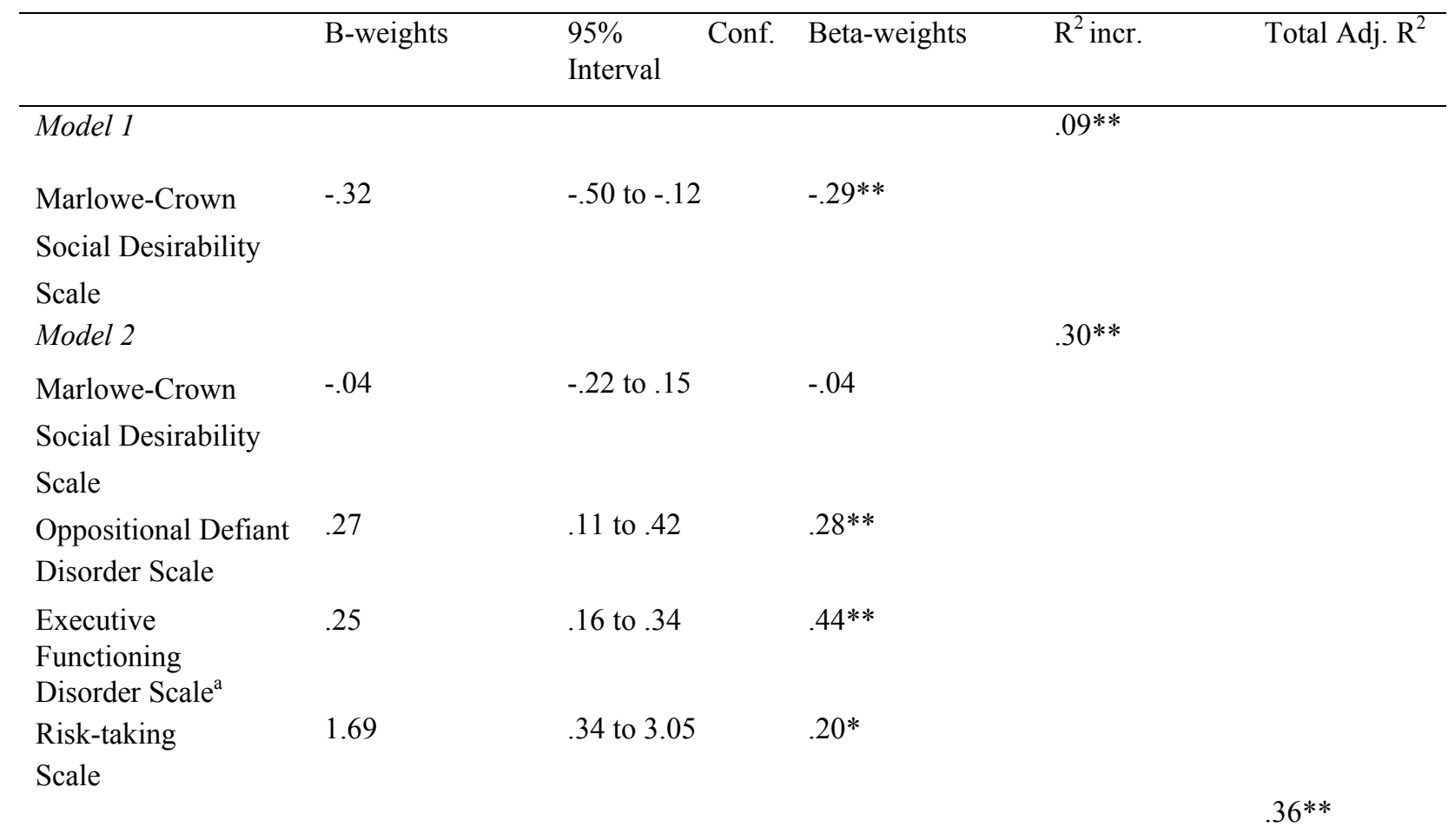

${ }^{\mathrm{a}}$ Measured by Barkley's Disorder of Executive Functions Subscale Factor 1: Self-Management-to-Time. ${ }^{+} \mathrm{p}$ $<.10>.05 ; * \mathrm{p}<.05 ; * * \mathrm{p}<.01$.

\subsubsection{Hyperactivity/Impulsivity}

In the $\mathrm{HI}$ analysis, the control variable accounted for $2 \%$ of the variance in Model 1 . For Model 2, only the ODD measure significantly entered the equation, while the other two measures were borderline significant. Altogether, the predictor variables accounted for $10 \%$ of the variance (the $\mathrm{R}^{2}$ increment after including the predictor variables $=.10$, and the total adjusted $\left.\mathrm{R}^{2}=.08\right)($ see Table 6$)$. Note that in contrast to the previous analyses, a much smaller amount of the variance was accounted for in the HI analysis. As would be expected, for the HI measure, the ODD predictor was the strongest (Murphy et al., 2002).

\subsubsection{Comparisons across Subscales}

It is quite interesting that the regression for the IA measure accounted for substantially more of the variance than the regression for the HI measure for this college sample. This may be explained in part by the fact that for the IA dependent measure, the beta-weight for the EF Self-Management-To-Time predictor (.44) was approximately three times as large as for the $\mathrm{HI}$ dependent measure (.16). In the ADHD diagnostic literature, poor management of time is typically associated more with an IA diagnosis than HI (Barkley \& Murphy, 2011; Kamradt et al., 2014). Thus, the present non-clinical findings are consistent with this pattern. 
Table 6. Predictors of Barkley's Hyperactivity-impulsivity subscale for the non-clinical community sample

\begin{tabular}{|c|c|c|c|c|c|}
\hline & B-weights & $\begin{array}{ll}95 \% & \text { Conf. } \\
\text { Interval } & \end{array}$ & Beta-weights & $\mathrm{R}^{2}$ incr. & Total Adj. $\mathrm{R}^{2}$ \\
\hline Model 1 & & & & .02 & \\
\hline $\begin{array}{l}\text { Marlowe-Crown } \\
\text { Social Desirability } \\
\text { Scale }\end{array}$ & -.15 & -.38 to .07 & -.13 & & \\
\hline Model 2 & & & & $.10^{* *}$ & \\
\hline $\begin{array}{l}\text { Marlowe-Crown } \\
\text { Social Desirability } \\
\text { Scale }\end{array}$ & .04 & -.21 to .28 & .03 & & \\
\hline $\begin{array}{l}\text { Oppositional Defiant } \\
\text { Disorder Scale }\end{array}$ & .24 & .03 to .45 & $.23^{*}$ & & \\
\hline $\begin{array}{l}\text { Executive } \\
\text { Functioning } \\
\text { Disorder Scale }^{\mathrm{a}}\end{array}$ & .10 & -.02 to .22 & $.16^{+}$ & & \\
\hline $\begin{array}{l}\text { Risk-taking } \\
\text { Scale }\end{array}$ & 1.67 & -.15 to 3.49 & $.17^{+}$ & & \\
\hline
\end{tabular}

${ }^{\mathrm{a}}$ Measured by Barkley's Disorder of Executive Functions Subscale Factor 1: Self-Management-to-Time. ${ }^{+} \mathrm{p}$ $<.10>.05 ; * \mathrm{p}<.05 ; * * \mathrm{p}<.01$.

However, what is somewhat surprising is that the ODD ratings show similar beta-weights for IA (.28) and HI (.23). Typically, with ADHD, those with HI show stronger ODD comorbidities (Murphy et al., 2002). This may be due to a difference in degree of severity of ODD behaviors between clinical and community samples. Among clinical samples, when individuals have both ADHD and ODD, they often show a combination of cognitive/behavioral problems typical of those with ADHD, and social-adversity, family-psychiatric, and family-conflict problems associated with ODD (Barkley et al., 1991; Jensen et al., 1997). In future research on ADHD/ODD comorbidity in community-based samples, it would be useful to compare HI and IA symptom-groups to determine whether they differ in family-conflict problems and social-adversity.

The present study is unique in examining risk-taking behaviors as an inclusive category across a wide range of types of risky behaviors in a non-clinical sample. In fact, we found that the different types of risky behaviors, including drug- and alcohol-abuse, gambling, risky driving, and risky sexual behaviors, all formed a coherent scale with a very good inter-item reliability. Further, this composite Risk-taking Scale did significantly predict scores on both the Combined and IA subscales, indicating, to some extent, the validity of the new scale. However, this scale was only a borderline significant predictor for the HI Subscale in the regression. The literature would suggest that a range of risk-taking behaviors should occur across IA, HI, and Combined ADHD subtypes (Barkley et al., 2002; De Alwis et al., 2014; Roberts et al., 2014; Sarver et al., 2014). Further research is needed to determine whether this composite measure of risk-taking is effectively capturing the type and extent of risk-taking among students, especially those higher on the HI subscale.

\subsection{Limitations}

One limitation of the present study is that the participants in this study were volunteers from a convenience college sample rather than from a random sample (with over-representation of individuals of above average intelligence). Furthermore, the students in this convenience sample showed a higher proportion of students fitting within the diagnostic cutoffs for each of the ADHD subscales relative to normative samples. The findings from the present study should be replicated using a more representative sample. It is possible that some individuals with ADHD were included in the sample, and some individuals without ADHD were excluded. For example, in the group of students who self-reported ADHD symptoms, it is not clear whether the symptom-onset was present before age 7, or if there was impairment present in two or more settings (the criteria for an ADHD child diagnosis.). 
In addition, the same rater was used for both the independent and dependent measures through the use of self-report. The use of self-report across measures is a common problem in studies of adult ADHD (Barkley, 1998). In the present study we chose to include a social desirability scale in order to reduce the possible confounding effects of negative response-bias tendencies among students rating themselves high on ADHD symptoms. Note, however, that this measure has somewhat lower reliability than is preferred (alpha $=.66$ rather than .70). Consequently, further investigation of this measure should be conducted to determine its effectiveness in controlling for student negative response biases.

\subsection{Conclusions}

The present findings address the major purpose of the study by showing that problem behaviors comorbid for a clinical diagnosis of ADHD are also significantly related to ADHD symptoms within a non-clinical sample. Other studies have found some evidence for individual associations between ADHD symptoms and one or more specific comorbid behaviors within community samples (e.g., Barkley \& Murphy, 2011; De Alwis et al., 2014). However, the contribution of the present study was to show that even within a non-clinical community sample, a strong relationship occurs across a range of constellations of behaviors that also have shown comorbidity with formal diagnoses of ADHD. These associations with ADHD symptoms extend across both externalizing and executive functioning problem behaviors. Specifically, these problem behaviors consist of: symptoms of Oppositional Defiant Disorders (ODD), as well as risk-taking in a number of domains (e.g., substance abuse, gambling, risk-taking associated with driving, and risky sexual activities), and also including Executive Functioning (EF) problems in terms of management of time. Furthermore, as would be expected from the ADHD literature, ODD behaviors were the strongest predictor of HI ADHD symptoms, and EF problems, involving poor management of time, were the strongest predictors of IA ADHD symptoms. Thus, a parallel was found between the characteristics associated with a clinical diagnosis of ADHD in the literature (Barkley, 1997a), and the characteristics predicting subclinical ADHD symptoms in the present community-based sample. These findings are consistent with the view that ADHD may be the extreme lower end of a normal continuum involving the ability to modulate attentional processes and behavioral inhibition/control (Barkley, 1998; Tannock, 1999).

In the treatment of ADHD, the criticism is often leveled that too many individuals are over-diagnosed as having ADHD. However, the present findings add to our understanding of individuals with borderline ADHD symptoms, and suggest that they have externalizing problems and atypical executive functioning related to those who fit the diagnosis. These findings suggest that even subclinical symptoms may have repercussions for the psychological wellbeing and functioning of normal individuals with this predisposition. Further research in this direction may be critical in treating this neglected group of individuals as well as providing a better understanding of the etiology of ADHD. These findings may be particularly useful for educators at the college level to understand that even without a diagnosis, students with ADHD symptomology may have substantial problems not only with their ADHD symptoms, but also with executive functioning and externalizing behaviors associated with these symptoms.

\section{Acknowledgements}

We would like to thank Ronald Nuttall, Ph.D., now deceased, for his development of the Risk-taking Scale based on items from the 1997 Youth Risk Behavior Survey from the CDC, and for his major contribution to the pilot research upon which this study is based. We would also like to thank Elizabeth Pezaris, Ph.D. for her important work on the earlier pilot research.

\section{References}

Abedi, A., Aghababaei, S., Sharbaf Zadeh, A., \& Zamani, N. (2014). Development of executive functions in 5to 12-years old Iranian children with and without ADHD. Journal of Educational and Developmental Psychology, 4(2). http://dx.doi.org/10.5539/jedp.v4n2p134

Abrantes, A. M., Strong, D. R., Ramsay, S. E., Kazura, A. N., \& Brown, R. A. (2006). HIV-risk behaviors among psychiatrically hospitalized with and without comorbid SUD. Journal of Dual Diagnosis, 2, 85-100. http://dx.doi.org/10.1300/J374v02n03_08

American Psychiatric Association. (1994). Diagnostic and statistical manual of mental disorders (4th ed.). Washington, D.C. American Psychiatric Association.

Barkley, R. A. (1997a). Inhibition, sustained attention, and executive functions: Constructing a unifying theory of ADHD. Psychological Bulletin, 121, 65-94. http://dx.doi.org/10.1037/0033-2909.121.1.65 
Barkley, R. A. (1997b). ADHD and the nature of self-control. New York: Guilford Press.

Barkley, R. A. (1998). Attention-deficit hyperactivity disorder: A handbook for diagnosis and treatment (2nd ed.). New York: The Guilford Press.

Barkley, R. A. (2011). Barkley Adult ADHD Rating Scale—IV (BAARS-IV). New York: The Guilford Press.

Barkley, R. (2012). Executive functions: What they are, how they work, and why they evolved. New York: The Guilford Press.

Barkley, R. A., Edwards, G., Laneri, M., Fletcher, K., \& Metevia, L. (2001). Executive functioning, temporal discounting, and sense of time in adolescents with Attention Deficit Hyperactivity Disorder (ADHD) and Oppositional Defiant Disorder (ODD). Journal of Abnormal and Child Psychology, 29, 541-556. http://dx.doi.org/10.1023/A:1012233310098

Barkley, R. A., Murphy, K. R., DuPaul, G. J., \& Bush, T. (2002). Driving in young adults with attention deficit hyperactivity disorder: Knowledge, performance, adverse outcomes, and the role of executive functioning. Journal of the International Neuropsychology Society, 8, 655-672. http://dx.doi.org/10.1017/s1355617702801345

Barkley, R. A., Fischer, M., Edelbrock, C. S., \& Smallish, L. (1991). The adolescent outcome of hyperactive children diagnosed by research criteria: I. An 8-year prospective follow-up study. Journal of the American $\begin{array}{llll}\text { Academy of Child and Adolescent Psychiatry, 29, 546-557. } & \text {. }\end{array}$ http://dx.doi.org/10.1097/00004583-199007000-00007

Barkley, R. A., Fischer, M., Smallish, L., \& Fletcher, K. (2006). Young adult outcomes of hyperactive children: Adaptive functioning in major life activities. American Academy of Child and Adolescent Psychiatry, 45, 192-202. http://dx.doi.org/10.1097/01.chi.0000189134.97436.e2

Barkley, R. A., Murphy, K. R., \& Kwasnik, D. (1996). Motor vehicle driving competencies and risks in teens and young adults with attention deficit hyperactivity disorder. Pediatrics, 98, 1089-1095.

Barkley, R. A., \& Murphy, K. R. (2011). The nature of Executive Function (EF) deficits in daily life activities in adults with ADHD and their relationship to performance on EF tests. Journal of Psychopathology and Behavioral Assessment, 33, 37-158. http://dx.doi.org/10.1007/s10862-011-9217-x

Biederman, J. et al. (1992). Further evidence for family-genetic risk factors in attention deficit hyperactivity disorder: Patterns of comorbidity in probands and relatives in psychiatrically and pediatrically referred $\begin{array}{lllll}\text { samples. } & \text { Archives }\end{array}$ http://dx.doi.org/10.1001/archpsyc.1992.01820090056010

Biederman, J. et al. (1993). Patterns of psychiatric comorbidity, cognition, and psychosocial functioning in adults with attention deficit hyperactivity disorder. American Journal of Psychiatry, 150, 1792-1798. http://dx.doi.org/10.1176/ajp.150.12.1792

Carragher, N., Krueger, R. F., Eaton, N. R., Markon, K. E., Keyes, K. M., Blanco, C. ... Hasin, D. S. (2014). ADHD and the externalizing spectrum: Direct comparison of categorical, continuous, and hybrid models of liability in a nationally representative sample. Social Psychiatry and Psychiatric Epidemiology, 49, 1307-1317. http://dx.doi.org/10.1007/s00127-013-0770-3

Crowne, D. P., \& Marlowe, D. (1960). A new scale of social desirability independent of psychopathology. Journal of Consulting Psychology, 24, 349-354. http://dx.doi.org/10.1037/h0047358

Crowne, D. P. (1979). The experimental study of personality. Hillsdale, NJ: Erlbaum.

Center for Disease Control. (1998). Youth 97. Springfield, VA: CDC/National Center for Chronic Diseas Prevention.

DeAlwis, D., Lynskey, M. T., Reiersen, A. M., \& Agrawal, A. (2014). Attention-deficit/hyperactivity disorder subtypes and substance use and use disorders in NESARC. Addictive Behaviors, 39, 1278-1285. http://dx.doi.org/10.1016/j.addbeh.2014.04.003

Douglas, V. I. (1983). Attention and cognitive problems. In M. Rutter (Ed.), Developmental neuropsychiatry (pp. 280-329). New York: Guilford Press. 
Douglas, V. I., \& Peters, K. G. (1979). Toward a clearer definition of the attention deficit of hyperactive children. In G. A. Hale, \& M. Lewis (Eds.), Attention and cognitive development (pp. 173-248). New York: Plenum Press. http://dx.doi.org/10.1007/978-1-4613-2985-5_8

Flory, K., Molina, B. S., Pelham, W. E., Gnagy, E., \& Smith, B. (2006). Childhood ADHD predicts risky sexual behavior in young adulthood. Journal of Clinical Child and Adolescent Psychology, 35, 571-577. http://dx.doi.org/10.1207/s15374424jccp3504_8

Green, A. L., \& Rabiner, D. L. (2013). Prevalence and correlates of ADHD in college students: A comparison of diagnostic methods. Journal of Educational and Developmental Psychology, 3(1). http://dx.doi.org/10.5539/jedp.v3n1p124

Groen, Y., Gaastra, G. F., Lewis-Evans, B., \& Tucha, O. (2013). Risky behavior in gambling tasks in individuals with ADHD-A systematic literature review. PLoS ONE, 8(9). http://dx.doi.org/10.1371/journal.pone.0074909

Hulme, C., \& Snowling, M. J. (2009). Developmental disorders of language, learning, and cognition. Massachusetts: Wiley-Blackwell.

Jensen, P. S., Martin, D., \& Cantwell, D. P. (1997). Comorbidity in ADHD: Implications for research, practice, and DSM-V. Journal of the American Academy of Child and Adolescent Psychiatry, 36, 1065-1079. http://dx.doi.org/10.1097/00004583-199708000-00014

Kamradt, J. M., Ullsperger, J. M., \& Nikolas, M. A. (2014). Executive function assessment and adult attention deficit/hyperactivity disorder: Tasks versus ratings on the Barkley deficits in executive functioning scale. Psychological Assessment, 26, 1095-1105. http://dx.doi.org/10.1037/pas0000006

Kaye, S., Gilsenan, J., Young, J. T., Carruthers, S., Allsop, S., Degenhardt, L., ... van den Brink, W. (2014). Risk behaviours among substance use disorder treatment seekers with and without adult ADHD symptoms. Drug and Alcohol Dependence, 144, 70-77. http://dx.doi.org/10.1016/j.drugalcdep.2014.08.008

Levy, F., Hay, D., McStephen, M., Wood, C., \& Waldman, I. (1997). Attention-deficit hyperactivity disorder: A category or a continuum? Genetic analysis of a large-scale twin study. Journal of the American Academy of Child and Adolescent Psychiatry, 1, 121-124. http://dx.doi.org/10.1097/00004583-199706000-00009

Marcus, D. K., Norris, A. L., \& Coccaro, E. F. (2012). The latent structure of attention deficit/hyperactivity disorder in an adult sample. Journal of Psychiatric Research, 46, 782-789. http://dx.doi.org/10.1016/j.jpsychires.2012.03.010

Murphy, K. R., \& Barkley, R. A. (1996). Prevalence of DSM-IV symptoms of ADHD in adult licensed drivers. Journal of Attention Disorders, 1, 147-162. http://dx.doi.org/10.1177/108705479600100303

Murphy, K. R., Barkley, R. A., \& Bush, T. (2002). Young adults with attention deficit hyperactivity disorder: Subtype differences in comorbidity, educational, and clinical history. Journal of Nervous and Mental Disease, 190, 147-157. http://dx.doi.org/10.1097/00005053-200203000-00003

Newcorn, J. H., \& Halperin, J. M. (1994). Comorbidity among disruptive behavior disorders: Impact on severity, impairment, and response to treatment. Child and Adolescent Psychiatric Clinics of North America, 3, 227-252.

Price, M. N., \& Hyde, J. S. (2009). When two isn't better than one: Predictors of early sexual activity in adolescence using a cumulative risk model. Journal of Youth and Adolescence, 38, 1059-1071. http://dx.doi.org/10.1007/s10964-008-9351-2

Radonovich, K. J., \& Mostofsky, S. H. (2004). Duration judgments in children with ADHD suggest deficient utilization of temporal information rather than general impairment in timing. Child Neuropsychology, 10, 162-172. http://dx.doi.org/10.1080/09297040490911023

Reynolds, W. M. (1982). Development of reliable and valid short forms of the Marlowe-Crowne social desirability $\begin{array}{lllll}\text { scale. Journal of } & \text { Clinical } & \text { Psychology, } & 38, & 119-125 .\end{array}$ http://dx.doi.org/10.1002/1097-4679(198201)38:1<119::AID-JCLP2270380118>3.0.CO;2-I

Roberts, W., Peters, J. R., Adams, Z. W., Lynam, D. R., \& Milich, R. (2014). Identifying the facets of impulsivity that explain the relation between ADHD symptoms and substance use in a nonclinical sample. Addictive Behaviors, 39, 1272-1277. http://dx.doi.org/10.1016/j.addbeh.2014.04.005 
Rugle, L., \& Melamed, L. (1993). Neuropsychological assessment of attention problems in pathological gamblers. Journal of Nervous \& Mental Disease, 181, 107-112. http://dx.doi.org/10.1097/00005053-199302000-00006

Sarver, D. E., McCart, M. R., Sheidow, A. J., \& Letourneau, E. J. (2014). ADHD and risky sexual behavior in adolescents: Conduct problems and substance use as mediators of risk. Journal of Child Psychology \& Psychiatry, 55, 1-9. http://dx.doi.org/10.1111/jcpp.12249

Tannock, R. (1999). Attention deficit hyperactivity disorder: Advances in cognitive, neurobiological, and genetic

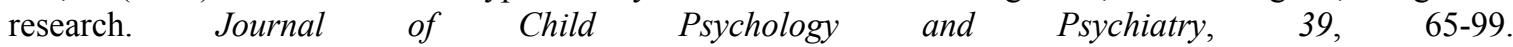
http://dx.doi.org/10.1017/S0021963097001777

Toplak, M. E., Jain, U., \& Tannock, R. (2005). Executive and motivational processes in adolescents with Attention-Deficit-Hyperactivity Disorder (ADHD). Behavior and Brain Functions, 1(8), 1-12. http://dx.doi.org/10.1186/1744-9081-1-8

Toplak, M. E., Dockstader, C., \& Tannock, R. (2006). Temporal information processing in ADHD: Findings to date and new methods. Journal of Neuroscience Methods, 151, 5-29. http://dx.doi.org/10.1016/j.jneumeth.2005.09.018

Toplak, M. E., West, R. F., \& Stanovich, K. E. (2013). Practitioner review: Do performance-based measures and ratings of executive functions assess the same construct? Journal of Child Psychology and Psychiatry, 54(2), 131-143. http://dx.doi.org/10.1111/jcpp.12001

Weiss, G., \& Hectman, L. T. (1993). Hyperactive children grown up: ADHD in children, adolescents, and adults (2nd ed.). New York: The Guilford Press.

White, J. W., \& Buehler, C. (2012). Adolescent sexual victimization, ADHD symptoms, and risky sexual behavior. Journal of Family Violence, 27, 123-132. http://dx.doi.org/10.1007/s10896-012-9411-y

Willcutt, E. G., Doyle, A. E., Nigg, J. T., Faraone, S., \& Pennington, B. F. (2005). Validity of the executive function theory of attention-deficit/hyperactivity disorder: A meta-analytic review. Biological Psychiatry, 57, 1336-1346. http://dx.doi.org/10.1016/j.biopsych.2005.02.006

\section{Appendix}

\section{Risk-Taking Behaviors Questionnaire}

Instructions: Check the box that best

describes your behavior.

\section{Risk-taking in Cars}

How often do you wear a seat belt when riding in a car?

Never

Rarely

Sometimes

Most of the time

Always

During the past 30 days, how many times did you ride in a car or other vehicle driven by someone who had been drinking alcohol?
0 times
1 time
2 or 3 times
4 or 5 times
6 or more times

During the past 30 days, how many times did you drive a car or other vehicle when you had been drinking alcohol? 0 times 
1 time

2 or 3 times

4 or 5 times

6 or more times

During the past 30 days, how many times did you drive a car or other vehicle faster than 100 miles per hour?

0 times

1 time

2 or 3 times

4 or 5 times

6 or more time

During the past 6 months, how many times did you have an accident while driving a car or other vehicle?

0 times

1 time

2 or 3 times

4 or 5 times

6 or more times

During the past 6 months, how many times did you get a traffic ticket for a moving violation while driving a car?

0 times

1 time

2 or 3 times

4 or 5 times

6 or more time

\section{Excessive Gambling}

How often in the past 30 days have you gambled more than $\$ 500$ on one bet?

0 times

1 to 9 times

10 or more times

During the past six months, how many days have you gambled over $\$ 100$ at a casino or on the horses?

0 days

1 day

2 to 5 days

6 to 9 days

10 or more days

Would others consider you to be a regular gambler?

Certainly not

Probably not

Perhaps

Probably yes

Certainly yes

During the past 30 days, how many days have you spent most of the day and night gambling, playing computer games, or on face book?

0 days 
1 day

2 days

3 to 9 days

10 to 19 days

20 or more days

\section{Excessive Drinking}

During the past 30 days, on how many days did you have 5 or more drinks of alcohol in a row, that is, within a couple of hours?
0 days
1 day
2 days
3 to 5 days
6 to 9 days
10 to 19 days
20 or more days

How many days in a row, during the past 30 days, did you have 5 or more drinks of alcohol?
0 days
1 day
2 days
3 to 5 days
6 to 9 days
10 to 19 days
20 or more days

\section{Drug Use}

During the past 30 days, how many times did you use marijuana?
0 times
1 or 2 times
10 to 19 times
20 to 39 times

40 or more times

During the past 30 days, how many times did you use any form of cocaine, including powder, crack, or freebase?
0 times
1 or 2 times
10 to 19 times
20 to 39 times
40 or more times

During the past 30 days, how many times have you used any other type of recreational drug, such as LSD, PCP, ecstasy, Molly, mushrooms, speed, ice, heroin or snorted Ritalin, Meth, or any other stimulant medication?
0 times +
1 or 2 times
10 to 19 times
20 to 39 times 
40 or more times

During the past 30 days, how many times have you used any recreational drug in combination with drinking alcohol?

0 times

1 to 9 times

10 to 19 times

20 to 39 times

40 or more times

\section{Risky Sexual Behavior}

During the past 30 days, how many times did you have sexual intercourse?

0 times

1 time

2 or 3 times

4 to 9 times

10 to 19 times

20 or more times

During the past 30 days, how often did you or your partner use a condom?

I have not had sexual intercourse during the past 30 days

Never used a condom

Rarely used a condom

Sometimes used a condom

Most of the time used a condom

Always used a condom

How many times have you been pregnant or gotten someone pregnant?

0 times

1 time

2 or more times

\section{Copyrights}

Copyright for this article is retained by the author(s), with first publication rights granted to the journal.

This is an open-access article distributed under the terms and conditions of the Creative Commons Attribution license (http://creativecommons.org/licenses/by/3.0/). 